\section{Pile Irradiation of Polyethylene Terephthalate ('Terylene')}

IN view of its bearing on the recent communication from Miss Little ${ }^{1}$, some simultaneous and independent work, initiated by Charlesby's claim to have crosslinked polyethylene terephthalate by pile irradiation ${ }^{2}$, is perhaps worth recording.

The solution viscosities of two ethylene terephthalate polymers, both before and after varying amounts of irradiation in the BEPO pile at the Atomic Energy Research Establishment, Harwell, were measured in $o$-chlorophenol at $25^{\circ} \mathrm{C}$. One polymer ('microdull') contained titanium dioxide as a delustring agent but there was none in the other ('bright'). For both polymers, the limiting viscosity number [ $\eta$ ] fell and the Huggins's viscosity slope constant $^{3}$,

$$
k^{1} H=\frac{\mathrm{d}\left(\frac{\eta-\eta_{0}}{\eta_{0} c}\right)}{\mathrm{d} c} /[\eta]^{2},
$$

where $\eta$ and $\eta_{0}$ are the viscosities of solution and solvent respectively and $c$ is the concentration of the solution in gm. $/ \mathrm{ml}$., rose with increase of radiation dose. It should perhaps be noted that hydrolysis will contribute to the $[\eta]$ drop for the samples of bright polymer irradiated longest in sealed tubes if the temperature in the pile approaches $100^{\circ} \mathrm{C}$.

\begin{tabular}{|c|c|c|c|}
\hline Polymer & $\begin{array}{l}\text { Radiation energy } \\
\left(\mathrm{MW} . \mathrm{hr} . \times 10^{2}\right)\end{array}$ & {$\left[\eta_{l}\right]$} & $k^{1} B$ \\
\hline $\begin{array}{c}\text { Microdull } \\
\text { ", } \\
\text { Bright } \\
\text { ", } \\
\text { ", }\end{array}$ & $\begin{array}{l}0 \\
0 \cdot 3 \text { in air } \\
0.5 \quad " \\
1 \cdot 0 \quad " \\
2 \cdot 0 \quad " \\
0 \\
2 \\
4 \\
8 \quad \text { in vacuo } \\
8\end{array}$ & $\begin{array}{l}76 \\
65 \\
62 \\
57 \\
52 \\
65 \\
49 \\
42 \\
37\end{array}$ & $\begin{array}{l}0.25 \\
0.39 \\
0.41 \\
0.43 \\
0.38 \\
0.27 \\
0.43 \\
0 * 53 \\
0.52\end{array}$ \\
\hline
\end{tabular}

Although the exact significance of $k^{1} H$ is not clear, it is generally agreed that it depends on the interactions between the molecules in high polymer solutions : a rise in $k^{1}{ }_{H}$ would correspond to a reduction in the effectiveness of o-chlorophenol as a solvent for the polymer. The exponent $\alpha$, which is thought to be unity for spinning-grade polyethylene terephthalate (W. R. Throssell, unpublished work), in the relation between [ $\eta$ ] and number average molecular

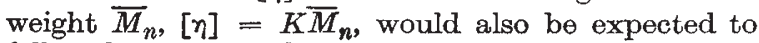
fall and cause a reduction in [ $\eta]$ uncompensated by the accompanying rise in $K$. Hence, the observed drop in [ $\eta]$ does not necessarily indicate a reduction in $\bar{M}_{n}$, although the magnitude of the effect suggests that this is probable.

The samples which had been more heavily irradiated in vacuo show a small but significant decrease in Vicat softening point of $0.27^{\circ} \mathrm{C}$. for unit fall in [ $\gamma$ ]. This would be consistent with a modification of the chain structure, for example, by branching. It could be caused by occluded degradation products, but these would probably be removed during the crystallizing pretreatment for one hour at $140^{\circ} \mathrm{C}$. before the softening-point test. It cannot be due merely to a reduction in molecular weight, for a fall in softening point is not detected in samples produced by hydrolysis of normal polyethylene terephthalate until [ $\eta]$ falls below about 30 .

In agreement with the conclusions from X-ray data ${ }^{1}$, these results suggest that the effect of pile radiation, at least up to $800 \mathrm{MW}$. hr., on polyethylene terephthalate is degradative, although possibly accompanied by branching. Furthermore, the relative ease of solution, unchanged by irradiation, of all the samples in $o$-chlorophenol, together with the lowered softening point are inconsistent with the presence of any measure of cross-linking as reported by Charlesby ${ }^{2}$.

Research Department,

AUdREY TODD*

'Terylene' Council,

Imperiol Chemical Industries, Ltd., Black Fan Road,

Welwyn Garden City, Hertfordshire.

* Present address: Department of Chemistry, Cornell University, Ithaca, New York, U.S.A.

${ }^{1}$ Little, K., Nature, 173, 680 (1954).

${ }^{2}$ Charlesby, A., Nature, 171, 167 (1953).

${ }^{3}$ Huggins, M. L., J. Amer. Chem. Soc., 64, 2716 (1942).

\section{A Corrected Guldberg Rule}

According to the well-known rule of Guldberg ${ }^{1}$, the normal boiling point of a liquid is two-thirds of the critical temperature on the absolute scale. The rule is not obeyed by liquids of low boiling point ${ }^{2}$, and even for liquids boiling in the range $20-250^{\circ} \mathrm{C}$. the ratio $T_{b} / T_{c}$ varies from $0 \cdot 58$ to $0 \cdot 70$. Inasmuch as these deviations arise from the different cohesive forces, and the latter are related to the surface tension, we may write

$$
T_{b} \gamma_{b}^{n} / T_{c}=k,
$$

where $\gamma_{b}$ is the surface tension of the liquid at the boiling point, and $n$ and $k$ are constants. For ordinary organic liquids the relation

$$
T_{b} \gamma_{b}^{\frac{1}{z}} / T_{c}=4 / 3
$$

\begin{tabular}{|c|c|c|}
\hline Substance & $T_{b} / T_{c}$ & $T b \gamma_{b}^{\frac{1}{2}} / T_{c}$ \\
\hline $\begin{array}{l}\text { Carbon disulphide } \\
\text { Ethyl bromide } \\
\text { Benzene } \\
\text { 1.1-Dichloroethane } \\
\text { Cyclohexane } \\
\text { Ethyl ether } \\
n \text {-Propyl formate } \\
\text { Methyl butyrate } \\
\text { isoAmyl formate } \\
n \text {-Butyl acetate } \\
n \text {-Octane }\end{array}$ & $\begin{array}{l}0.586 \\
0.618 \\
0.629 \\
0.633 \\
0.640 \\
0.658 \\
0.663 \\
0.677 \\
0.688 \\
0.690 \\
0.700\end{array}$ & $\begin{array}{l}1 \cdot 338 \\
1 \cdot 335 \\
1 \cdot 348 \\
1 \cdot 348 \\
1 \cdot 316 \\
1 \cdot 305 \\
1 \cdot 355 \\
1 \cdot 349 \\
1 \cdot 344 \\
1 \cdot 342 \\
1 \cdot 303\end{array}$ \\
\hline
\end{tabular}

is generally more accurate than the simple Guldberg rule, as may be seen from the following data:

A relation between the parachor and the critical volume may be derived from (1). Since the molar volume of a liquid at the boiling point is three-eighths of the critical volume ${ }^{3}$, we have

$$
\frac{T_{b} \gamma_{b}^{\frac{1}{b}} V_{b}}{T_{c} V_{c}}=\frac{1}{2}
$$

so that the parachor is given by

$$
P=\frac{1}{2} \frac{V_{c} T_{c}}{T_{b}}
$$

A study of the experimental data led Ferguson and Kennedy ${ }^{4}$ to propose the empirical formula

$$
P=0 \cdot 324 V_{c}^{\frac{7}{8}} T_{c}^{\frac{1}{4}},
$$

